Florida International University FIU Digital Commons

7-25-2003

\title{
Hospital discharge planning in the provision of food and nutrition services for older adults post discharge
}

Etty B. Baker

Florida International University

DOI: $10.25148 /$ etd.FI14050411

Follow this and additional works at: https:// digitalcommons.fiu.edu/etd

Part of the Dietetics and Clinical Nutrition Commons

\section{Recommended Citation}

Baker, Etty B., "Hospital discharge planning in the provision of food and nutrition services for older adults post discharge" (2003). FIU Electronic Theses and Dissertations. 1374.

https://digitalcommons.fiu.edu/etd/1374 
FLORIDA INTERNATIONAL UNIVERSITY

Miami, Florida

HOSPITAL DISCHARGE PLANNING IN THE PROVISION OF FOOD AND NUTRITION SERVICES FOR OLDER ADULTS POST DISCHARGE

\author{
A thesis submitted in partial fulfillment of the \\ requirements for the degree of \\ MASTER OF SCIENCE \\ in \\ DIETETICS AND NUTRITION \\ by
}

Etty B. Baker

2003 
To: Dean Ronald M. Berkman

College of Health and Urban Affairs

This thesis, written by Etty B. Baker, and entitled Hospital Discharge Planning in the Provision of Food and Nutrition Services for Older Adults Post Discharge, having been approved in respect to style and intellectual content, is referred to you for judgment.

We have read this thesis and recommend that it be approved.

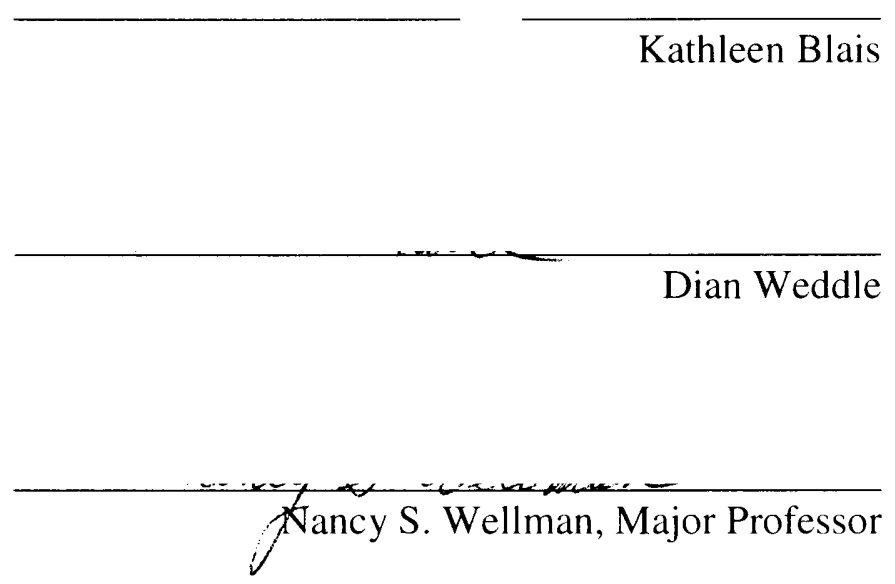

Date of Defense: July 25, 2003

The thesis of Etty B. Baker is approved.

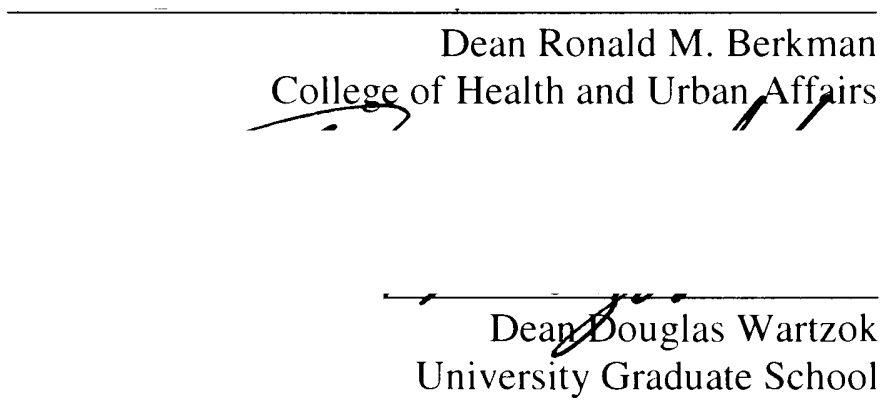

Florida International University, 2003 


\section{DEDICATION}

This thesis is dedicated to my wonderful mother who taught me the value of education from a very early age. I vividly remember waking up in the middle of the night, only to find her diligently studying. She had three jobs while attending college, and maintained a 4.0 average for many years, in hopes of creating a better life for the two of us. She never complained and made everything seem so effortless. She was a single mother, with no external support, in a time when it was not so common. In such selfless and unconditional ways, she made sure I had everything.

Thank you, mom, for teaching me the value of independence. Your strength, courage, and optimism continue to inspire me. Thank you for always believing in me, for loving me unconditionally, and for your emotional and financial support throughout this process. 


\section{ACKNOWLEDGMENTS}

I wish to thank my wonderful family and friends, near and far, for encouraging me during my academic pursuits. I want to thank my amazing boss and friend, Mary, for being so accommodating with my work schedule and for being so supportive. I want to thank my colleague and friend, Danielle, for motivating me and helping me in every way, at any time. I want to thank my other colleague and friend, Kelly, for making me laugh and promising me that this process would be over before I knew it!

I wish to thank my committee members, Dr. Weddle and Dr. Blais, for their expertise, support, and time. Most of all, I wish to thank my mentor and major professor, Dr. Wellman, for being my complete support system throughout this process, and for never doubting my abilities. She continues to inspire me with her brilliance, creativity, and impeccable writing ability. She undoubtedly sets the highest standard for women to follow. 


\begin{abstract}
OF THE THESIS
HOSPITAL DISCHARGE PLANNING IN THE PROVISION OF FOOD AND NUTRITION SERVICES FOR OLDER ADULTS POST DISCHARGE by
\end{abstract} Etty B. Baker

Florida International University, 2003 Miami, Florida

Professor Nancy S. Wellman, Major Professor

This descriptive study examined whether discharge planning ensures that food and nutrition services are provided to older adults following hospital discharge. The questionnaire was distributed to discharge planning professionals in 11 South Florida hospitals. Of the 84 respondents ( $88 \%$ response rate), most were female nurse case managers. Almost all reported job barriers including excessive patient loads, too many responsibilities, and limited community services. While physicians, registered nurses, social workers, physical therapists, were deemed "very important" in discharge planning, registered dietitians were not, and almost half consulted them infrequently, if at all. Over $84 \%$ said nutrition-related medical conditions/factors, "strongly influenced" discharge planning. Many did not have adequate information about nutrition-related community resources, eg, home delivered meals, food stamps, outpatient registered dietitians. There were no universal approaches in meeting the nutrition needs in 6 case scenarios. More communication among community services and hospitals is needed. 


\section{LIST OF TABLES}

TABLE

PAGE

Table 1: Characteristics of discharge planning professionals. . . . . . . .

Table 2: Average daily case load, time spent in discharge planning, and perceived barriers by discharge planning professionals.

Table 3: Healthcare professionals deemed "very important" to discharge planning professionals in the discharge planning process.

Table 4: Time spent by discharge planning professionals in consulting healthcare professionals. . . . . . . . . . . . . . . . . . . .

Table 5: Nutrition-related factors and resources affecting post discharge care. . . 


\section{Chapter 1}

\section{Introduction and Research Questions}

Older adults, aged 65 and over, are the fastest growing population group in the $21^{\text {st }}$ century. This population group is anticipated to increase by $17 \%$, from 1995 to 2010 and by $75 \%$ from 2010 to 2030 . By 2050 , older adults will account for 79 million people in this country (1). In 1996, $27 \%$ of older adults assessed their health as fair to poor (2).

Issues regarding the current healthcare system in the United States and its ability to effectively care for older adults are under heavy scrutiny. With managed care limitations and the development of Medicare's Prospective Payment System (PPS) in 1983 , quality of care is in serious question. The PPS is a fixed-fee system based on diagnosis related groups (DRGs). It contains incentives to reduce length of stay and substitutes lower cost services for more expensive ones. However, research suggests that the PPS has increased the likelihood that a patient will be discharged home in an unstable condition (3). According to C.M. Mullahy, a nationally recognized case management consultant, "opportunities to improve outcomes for patients and families and save substantial dollars have been lost. We are sending people home much quicker and sicker"(4).

While length of hospital stay had decreased by $18 \%$ from 1981 to 1991, Medicare beneficiaries account for at least one quarter of all hospital readmissions $(5,6)$. Hospital readmission rates for older adults range from $24 \%-55 \%$ and are higher in cost compared to the first admission (7). Furthermore, while managed care is striving to provide quality of care in a shorter time frame, malnutrition is common among hospitalized older adults. Malnutrition has been estimated to affect more than $40 \%$ of older hospitalized adults and 
significantly correlates with increased length of stay, readmission rates, and mortality $(8,9)$. Given these circumstances, there is little doubt that gaps exist in the current healthcare system.

Discharge planning is a strategy that attempts to provide patients with a continuum of care and services post-discharge. With the cost-containment issues that surround healthcare, effective discharge planning is viewed as one way to balance cost with quality (10). Even though this process may be viewed as extremely time consuming, it is a crucial step in assuring continuity of care for older adults post discharge. Still, this process remains ill-defined (10). According to L. Nazarko, "For over 25 years, there have been reports of inadequate discharge planning methods which include poor interprofessional cooperation, poor documentation, inadequate patient consultation and communication difficulties"(11). Given that older adults have increased discharge planning needs as a result of possible social, financial, physical and/or medical needs, research has suggested that a more collaborative, comprehensive discharge planning process can produce better outcomes in terms of cost and quality of care $(5,12,13)$. This collaborative and comprehensive approach extends far beyond hospital walls and into the community setting. According to the Administration on Aging (AoA), 2 of the 9 million Americans over the age of 65 who live alone say they have no one to turn to if they need help (14).

Nutrition is effective in maintaining quality of life and health status in the later years (15). Community programs exist for this population group to help maintain their health, well-being, and independence (16). Some may indirectly or directly provide food and nutrition services, which is important as a significant percentage of older adults have 
difficulty with activities of daily living (ADLs) and instrumental activities of daily living (IADLs). These functional limitations could impede their ability to have a good quality of life if community systems are not in place when transitioning home from the hospital.

The purpose of this study was to examine how hospital discharge planners ensure that food and nutrition services are met following hospital discharge. This study was done to determine which, if any, gaps exist in the provision of food and nutrition services in the continuum of care process. This will help dietitians and other healthcare professionals recognize areas that need improvement. The following research questions were asked.

\section{Research Questions}

1. What factors do discharge planning professionals view as impacting the need for food and nutrition services post discharge for older adults?

2. What are the strategies/methods that discharge planning professionals use to help ensure that food and nutrition needs of older adults are met post discharge?

3. What other healthcare disciplines, if any, do discharge planning professionals consult in the discharge planning process?

4. What information do discharge planning professionals have about food and nutrition programs available within the community?

5. What do discharge planning professionals believe about the adequacy of food and nutrition resources that are available for older adults within the community? 


\section{References}

1. Administration on Aging. Aging into the $21^{\text {st }}$ Century. Available at: http://www.aoa.dhhs.gov/aoa/stats/aging21/demography.html Accessed February 3, 2001.

2. Administration on Aging. Profile of Older Americans: 2000. Available at: http://www.aoa.gov/aoa/stats/profile/default.htm Accessed April 18, 2001.

3. Rogers W, Draper D, Kahn K, Keeler E, Rubenstein L. Kosecoff J, Brook R. Quality of care before and after implementation of the DRG-based prospective payment system, a summary of effects. JAMA. 1990;264:1989-1994.

4. Mullahy $\mathrm{C}$. The effective integration of utilization and case management. TCM. 2000:53-56.

5. Naylor M, Brooten D, Jones R, Lavisso-Mourey R, Mezey M, Pauly M. Comprehensive discharge planning for the hospitalized elderly, a randomized clinical trial. Ann Intern Med. 1994;120:999-1006.

6. Vinson JM, Rich MW, Sperry JC, Shah AS, McNamara T. Early readmission of elderly patients with congestive heart failure. J Am Geriatr Soc. 1990;39:1045-1046.

7. Zook CJ, Savickis SF, Moore FD. Repeated hospitalization for the same disease: a multiplier of national health costs. Milbank Mem Fund $Q$ 1980;58:454-471.

8. Chima CS, Barco K, Dewitt MLA, Maeda M, Teran JC, Mullen KD. Relationship of nutritional status to length of stay, hospital costs, and discharge status of patients hospitalized in the medicine service. J Am Diet Assoc. 1997;97:975-978.

9. Sullivan $\mathrm{DH}$, Walls RC. Protein-energy undernutrition and the risk of mortality within six years of hospital discharge. J Am Coll Nutr. 1998;17:571-578.

10. Wayman C. Hospital-based nursing case management role clarification. Nurs Case Manag. 1999:236-241.

11. Nazarko L. Improving hospital discharge arrangements for older people. Nurs Stand. 1997;11:44-47. 
12. Naylor MD, Brooten D, Campbell R, Jacobsen BS, Mezey MD, Pauly MV, Schwartz JS. Comprehensive discharge planning and home follow-up of hospitalized elders, a randomized clinical trial. JAMA. 1999;281:613-620.

13. Naylor MD. Comprehensive discharge planning for hospitalized elderly: a pilot study. Nurs Res. 1990:156-161.

14. Administration on Aging. The Administration on Aging and the Older Americans Act. Available at: http://www.aoa.gov/aoa/pages/aoafact.html Accessed March 5, 2001.

15. Weddle DO, Fanelli-Kuczmarski M. Position of the American Dietetic Association: nutrition, aging, and the continuum of care. J Am Diet Assoc. 2000;100:580-596.

16. Elder Affairs Programs and Services. Available at: http://www7.myflorida.com/doea.healthfamily/learn/elderpr.../doeprogramsandservic es.htm Accessed April 18, 2001. 


\section{Chapter II \\ Literature Review}

\section{Aging Demographics}

As we moved into the $21^{\text {st }}$ century, the aging of America and issues surrounding the adequacy of our healthcare system have become national concerns. During the last century, there was considerable growth in numbers of older adults in the United States. According to the United States Administration on Aging, from 1900 to 1999, the number of older adults increased by 11 fold, from 3.2 million to 34.5 million (1). These numbers will continue to grow as the baby boomer generation reaches older adulthood. By 2010, there will be 39.4 million older adults. Between 2010 and 2030, the number will grow by $75 \%$ to 69 million. By 2050 , there will be 79 million older adults (2). Based on these numbers, an effective and comprehensive healthcare system is needed to ensure the safety, well-being, and quality of life of older adults in America.

\section{Healthcare Utilization}

Healthcare costs can be overwhelming and may inhibit older adults from obtaining the necessary comprehensive care. Of 32 million older adults reporting income in $1999,34 \%$ reported less than $\$ 10,000$ during that year. The median annual income reported was $\$ 14,425$ with approximately 3.2 million older adults living below the poverty line (1). In 1998 , older adults, on average, spent $52 \%$ for insurance, $22 \%$ for drugs, $20 \%$ for medical services and $5 \%$ for medical supplies (1). In addition to financial hardships, chronic diseases can, and often do, debilitate them. In 1997, among those 6574 years old, $30 \%$ had limitations caused by a chronic condition. Over half of those 75 years and older reported the same (1). Over $25 \%$ of older adults rated their health as fair 
to poor (1). In 1997, older adults accounted for 39\% of all hospital stays (1). Although length of stay has decreased by 5.3 days since 1964 , older adults spent $12 \%$ of their total expenditures on health, 3 times the proportion spent by younger consumers (1).

\section{The Prospective Payment System}

The Prospective Payment System (PPS), which began in the 1980s, pays hospitals amounts based on flat rates per admission. These flat rates are based on each of approximately 470 diagnosis related groups (DRGs) (3). While providing capitated amounts of money, the PPS also offers incentives to decrease length of hospital stay and substitute lower cost services and procedures for more expensive ones. As a result of this system, quality of care has been questioned.

A series of retrospective studies, by the Health Care Financing Act (HCFA) and the US Department of Health and Human Services (DHHS) were conducted to evaluate the effectiveness and implications of the PPS. Target audiences included clinicians who wanted to improve the quality of care for hospitalized patients and public policy makers who wished to improve the health care system.

One study examined whether patients were discharged from hospitals in unstable conditions prior to and post PPS implementation (4). The sample included 10,913 subjects. Instability was 1 of 3 outcomes measured. An unstable condition was defined as clinical problems not present at admission. Of those patients discharged home, $43 \%$ were more likely to be unstable post-PPS. The authors noted that instability could have increased the risk of mortality (4).

As the aging of America continues, healthcare needs and associated costs continue to escalate. Better strategies are needed. Discharge planning, mandated by The 
Joint Commission on Accreditation of Healthcare Organizations (JCAHO), evolved in a time of decreasing reimbursements and increasing accreditation requirements. Hospital administrators view discharge planning as one way of balancing quality of care and $\operatorname{cost}(5)$.

\section{Critiques of the Discharge Planning Process}

Discharge planning can be defined as a team of various disciplines working with the patient and family to coordinate a smooth transition of care from one environment to the next (6). Inadequate discharge planning methods that include poor interprofessional cooperation, poor documentation, inadequate patient consultation, and communication have been reported for over 25 years (7). The ill-defined role (5) of the discharge planning professional is problematic as they are a critical component of the Medicare's PPS and its subsequent decreased length of hospital stay. The need for improved discharge planning is well recognized (8).

The purpose of discharge planning is to provide continuous care post discharge while, at the same time, staying within cost containment parameters by decreasing length of stay. This process has been critiqued throughout the years $(5,7,8)$. A 1980s panel of experts identified priorities for providing quality of care to older adults. Priorities were measured on a five point likert scale, optional choices ranging from "5" to 1." Five was the most favorable option. The panel defined adequate discharge planning as a priority and rated hospital discharge planning as highly beneficial " 5 ," definitely improvable "5," and the current quality as low "1" (9).

Hospital readmissions may be indicative of poor quality of care as a result of PPS constraints $(3,4)$, limited time for discharge planning professionals to get to know their 
patients (10), pressure to move patients out of the hospital quickly to make beds available, and lack of a comprehensive discharge planning approach targeted towards older adults (11-14).

\section{Hospital Readmissions}

According to Vinson and colleagues (1990), repetitive hospitalizations are common in older adults and account for $25 \%$ of all Medicare expenditures. In a study of 161 older adults, congestive heart failure (CHF) was the most common condition that caused hospitalizations. Therefore CHF and readmission rates were examined (15). Of 66 subjects discharged, $47 \%$ were readmitted within 90 days. Factors that contributed to readmission included noncompliance with medications and diet, inadequate discharge planning or follow-up, failed social support, and failure to seek medical attention as symptoms reappeared. Half of the readmissions could have been prevented if workable systems were in place (15).

Another study examined factors associated with unplanned hospital readmissions in Medicare Managed Care enrollees. The control and experimental groups were matched by diagnosis. The 5 factors significantly associated with readmission 30 days after initial discharge included age 80 and over, previous admission within 30 days, 5 or more medical comorbidities, history of depression, and 1 discharge factor which included lack of documented patient and/or family education programs (16).

Readmissions are costly. Clinical and financial issues associated with repeated admissions for the same disease have been examined (17). Medical records of 2, 238 subjects at 6 short stay hospitals were reviewed. Repeated hospitalizations occurred in each. Readmissions accounted for approximately $60 \%$ of all hospital charges. They were 
between $24 \%-55 \%$ more expensive compared to the first hospitalization. It was estimated that a $20 \%$ reduction in readmissions could save over $\$ 11$ billion dollars in hospital costs (17).

Early discharge often has financial implications (14). It has been associated with frequent emergency room visits, acute care visits, and home care nursing visits by Medicare beneficiaries, despite efforts to control costs by reducing length of stay. Home health care increased by 583\% from 1980-1991 (14).

Discharge Planning

The process of discharge planning is frequently complex. Often discharge planning is only a part of the job responsibilities held by case managers. According to R. Gutman, we are in an "era of cost containment and increased case loads for nurses, however, to be both successfully and professionally fulfilled, case management versions of nursing practice must be designed so nurses can get to know their patients"(18). Ramey and Daniels describe the typical day for case managers as one that includes approximately $30 \%$ of time spent discharge planning. Some of the responsibilities include "initiating and completing all required forms, verifying benefits and getting authorizations, sending patient information to at least three payment providers, copying charts, arranging transportation, contacting physicians to obtain transition orders and talking with a patient and family"(19). In addition, they must be aware of treatments, plans, progress and needs of the patient to coordinate efforts to shorten the recovery process while not compromising quality of care (20). Further, the important acute care stage is only a part of the process as care must extend beyond the hospital. A strategic overview of discharge planning has been defined as one that promotes good health, 
reduces lost bed days and readmission rates, reduces morbidity and oversees efficient and effective care for those who are ill (10). All must be accomplished within the DRG guidelines and strict time frames. Given this, providing thorough care can be further challenged as at risk population groups are on the rise (21). "The illiteracy rate, the frail elderly, Medicare coverage, social isolation, and financial vulnerability are additional issues that case managers must address"(21).

\section{Multidisciplinary Teams and Physician Involvement}

Multidisciplinary teams are needed to provide a holistic approach to patient care post discharge. "Ensuring that the threads from different strands of care are woven to provide 'seamless care' requires careful planning and coordination"(10). As the number of frail older adults continues to rise, effective teamwork is needed. Dietitians, physiotherapists, and speech and language therapists need to work with their community based colleagues (7). In one clinical trial study, multidisciplinary collaboration was one of the interventions that decreased the prevalence of functional decline in hospitalized, medically ill, older adult patients. Activities of daily living (ADLs) were significantly better at discharge, than on admission, for patients involved in the clinical trial compared to patients that received usual medical care (22).

One way to improve multidisciplinary relationships is effective communication, which includes written documentation. "Past research has shown that nursing records rarely detail a patient's previous level of function or home circumstances" (10). Without this comprehensive information, difficulties in making informed decisions may become an issue. To identify the cases that need more case management intervention, the right questions must be asked early in the process (21). Comprehensive information obtained 
on admission can be compromised if an older adult patient has an altered mental status such as dementia. In most cases, families may not be present to provide that necessary information. "Of the 9 million Americans over age 65 who live alone, 2 million say they have no one to turn to if they need help" (23).

Physicians tend to spend less time with geriatric patients and common geriatric problems can go undiagnosed or even unnoticed (24). In a Thailand study, the collaboration between discharge planning professionals and physicians were superficial as they had differing perceptions of discharge planning. For the physician, the word "discharge" may mean "job done." Communication between the physician and other members of the multidisciplinary team was insufficient and casual in nature. It was suggested that discharge planning be discussed more in depth during multidisciplinary rounds allowing for a more holistic approach to patient care (6).

\section{$\underline{\text { Home and Community Based Care }}$}

Knowledge of formal care, such as community services, is necessary for comprehensive discharge planning. In 1998, according to the Administration on Aging, approximately 9.9 million (31\%) of all non-institutionalized older persons lived alone (1). Yet a critical need exists for interventions in transitioning older adult hospitalized patients to their homes. These interventions include those that prevent poor outcomes after discharge and reduce health care costs (14).

Hospital discharge planning professionals and their perspectives on the discharge planning process were examined (25). They felt frustrated in their attempts to facilitate a continuum of care post discharge. At the same time, they felt that the process was dependent on effective communication between hospital and community staff. In 
addition, the discharge planning professionals called upon ongoing reviews of the discharge planning process, collaborative research, and support of nurses between sectors to increase knowledge of healthcare services (25).

Another study reviewed the challenges of community case managers in the provision of services to older adults (18). There was limited social and financial support within the community even though the frail elderly often have increased medical and social needs. Further, the community case managers lacked the knowledge and accessibility to formal services. These case managers were often physically and emotionally drained because the older adult needs extended far beyond the resources available. (18). According to Boling, "Care continuity is important, and discontinuity is a weakness in the US health care delivery, one that is perpetuated by funding mechanisms that do not align the interests of health care personnel in various settings" (8).

\section{$\underline{\text { Educational Needs }}$}

In a study by Nolan and associates (1998), 22 case managers were asked to identify the skills and knowledge that would be of value to future case managers. According to this study, little literature exists on how to best prepare nurses for case management roles. The top two educational needs identified were access to community resources and discharge planning (26). A goal was to determine how to improve educational programs in preparing nurses for case management roles. It was suggested that community program representatives provide inservices of available programs.

Czerenda and Best (1994) also recognized the need for better case management educational systems within the United Health Services, Inc. (UHS), based in New York. This system serves over 350,000 community members. The primary corporate goal is to 
provide a 'seamless continuum' of care. As health care delivery has moved away from the acute care setting and into the community, it was questioned whether available community services were really expanded systems of healthcare. Furthermore, within the UHS system, case managers often assume this role without a thorough understanding of it or the necessary skills needed to function effectively. Most training occurred by word of mouth or as on the job training. As a result, an improved educational program was developed. Together social workers and nurses devised the curriculum since individuals from both disciplines often assume case management roles.

The inexperienced case managers benefited from the educational content. The program successfully created a foundation for the continuity of care throughout the UHS system. An educational subcommittee was created to provide continuous educational programs. Some featured talks included case management experts and community providers. A newsletter to further enhance communication was developed. The UHS educational programs provided a variety of tools for case managers to better understand their clients and existing services along the continuum (27).

\section{$\underline{\text { Informal Caregiving }}$}

Older adults rely on informal caregivers, such as family and friends, for help after discharge (28). Yet, caregivers have felt that this burden is intolerable and they can feel very stressed (28). Older adults have felt ill-prepared returning home from the hospital. Jones and Lester (1994) examined opinions of both caregivers and patients about hospital care and discharge. There were 960 subjects who completed the questionnaire. Forty-six percent of caregivers and $38 \%$ of patients did not remember discussing discharge with hospital staff. These results were significant $(\mathrm{p}<.001)$. Fourteen percent of caregivers 
felt that discharge was too soon and, of that percentage, $56 \%$ felt that they were not sufficiently involved in discharge planning and aftercare coordination. Since informal caregivers care for many older adults, these individuals must be involved in discharge planning and making decisions (28).

Patient and family caregiver satisfaction is considered an important outcome measure of adequate discharge planning practices and often reflects quality of care (29). Satisfaction has been associated with adherence to treatment plans. Therefore, it potentially decreases readmission rates.

A study conducted by Bull and associates (2000) examined predictors of both older adult and family member satisfaction. One purpose was to provide clinicians with an understanding of the needs of this population group. Subjects were at least 55 years of age and hospitalized with heart failure. One hundred and thirty-four subjects along with their caregivers were included. Telephone interviews were conducted 2 weeks post discharge to determine if the discharge plans were meeting the needs of the patients. Perceptions of care continuity and preparedness were the best predictors of discharge planning satisfaction for both older adults and caregivers. When discrepancies existed with care received compared to expectations of care, tension caused dissatisfaction (29).

The impact of telephone follow up care by pharmacists was evaluated (30). The goal was to improve patient satisfaction by providing continued explanation of medications. Two hundred and twenty-one subjects were included. The significant findings indicated that the control group, which did not receive a follow up phone call from the pharmacist, returned to the emergency room more often than those in the experimental group (30). 


\section{Comprehensive Discharge Planning}

A comprehensive discharge plan specifically targeting older adults is one way to improve outcomes. Naylor and co-workers (1999) examined the benefits of a more intensive approach to follow up care by advanced practice nurses (APNs). There were 186 subjects in the control group and 177 subjects in the intervention group. Those in the control group received the standardized discharge planning protocol used for all patients, while the intervention group received an individualized comprehensive plan. Those in the intervention group were followed more closely while in the hospital and were followed at 2, 4, 6 and 12 weeks post discharge. Follow up included telephone calls and visits. As part of the comprehensive discharge plan, APNs addressed diet, medications, and activity level, and collaborated with physicians to address the appropriateness of care, make adjustments accordingly, and obtain referrals for needed services. The intervention group had fewer readmissions, fewer hospital days, and an increased length of time to first readmission. At 24 weeks post discharge, total Medicare reimbursements for health services were approximately $\$ 1.2$ million in the control group compared to $\$ 0.6$ million in the intervention group (14). Naylor and associates (1994) conducted an earlier study examining a similar concept but with gerontological nurse specialists. They followed older patients during the hospital stay as well as 2 weeks post discharge. Similar findings were reported (13).

Kennedy and colleagues (1987) also examined if outcomes would improve with the involvement of a geriatric clinical nurse specialist (GCNS) (11). Measured outcomes included length of stay, readmission rates within an 8 week time frame, and appropriateness of discharge plans as evidenced by no change in original plan, or change 
to a less dependent level of care, if indicated. Eighty subjects were divided into control and treatment groups. The GCNS provided a comprehensive plan to the treatment group including an in-depth look into health status, social needs, functional ability, resource use pattern, motivational level, and socioeconomic status. The GCNS met with patients, families, and multidisciplinary team members to develop optimal care plans. There was a significant decease in length of stay, readmission rates, and average days between discharge and the first readmission (11).

\section{Nutrition and Health Status}

Scientific evidence shows that sound nutrition is essential for health, maintaining independence, and quality of life for older adults (31). Diseases associated with dietary imbalances rank among the leading causes of illness and death in the United States (32). Research suggests that nutrition therapy is an integral component in the treatment and management of chronic diseases that affect the Medicare population (33). It has been estimated that $86 \%$ of Americans over the age of 65 have diabetes, dyslipidemia, hypertension or combinations of these conditions (33). These conditions, as well as kidney failure, heart failure, cancer, stroke, osteoporosis, pneumonia, wound healing, failure to thrive, immunity disorders, injury and fracture and congestive obstructive pulmonary disorder (COPD) benefit from nutrition therapy (32-34).

Even though good nutrition is essential in maintaining quality of life (31), malnutrition continues to be a common problem for this population group $(32,35-40)$. Malnutrition has been widely studied over the years and has serious health and financial consequences (35-40). Some indicators of malnutrition can be measured by 
laboratory values, weight status and history, clinical observations, and dietary values

(32). Research studies vary in the criteria defining malnutrition $(35,36,38)$.

\section{$\underline{\text { Prevalence and Consequences of Malnutrition }}$}

Compher, Kim and Bader (1998) discuss the decline in calorie consumption by older adults (41). It is difficult to meet vitamin and mineral requirements on less than $1,500 \mathrm{Kcal} /$ day; therefore, this decline may be problematic (41). Research suggests that older adults living alone do not consume adequate amounts of food (42). Approximately $40 \%$ of older adults have inappropriate dietary intake of 3 or more nutrients (32). Poorly nourished adults have higher morbidity, medical costs, length of hospital stay, readmission rates, and mortality $(17,35-40)$ which can both escalate costs and diminish quality of life.

Gallagher and colleagues (1996) reviewed studies of 1,327 hospitalized older adults. Forty to fifty-five percent were found to be either malnourished or at risk for malnutrition. Total protein level, serum albumin level, lymphocyte count, hematocrit levels, and weight loss were considered the best predictors of malnutrition. Malnutrition was associated with negative health outcomes such as slower healing rates, more complications, and mortality. Yet, nutrition intervention decreased complications such as morbidity, mortality, length of hospital stay with a cost reduction in overall resources. Reasons for malnutrition included disease states and social conditions that prevented older adults from purchasing, preparing, or consuming food. The percentage of weight loss was the strongest predictor of mortality within 1 year of hospital discharge (39) 
Sullivan and Walls (1998) determined that protein-energy undernutrition (PEU) was a risk factor for mortality after one year of hospital discharge among older adults. High nutrition risk was defined as an albumin of $30 \mathrm{~g} / \mathrm{L}$ and a Body Mass Index (BMI) of less than 19. Three hundred and twenty two older adults were tracked over a 6-year period. PEU present at hospital discharge appeared to be a strong independent risk factor for mortality (36).

Thomas and colleagues (2002) examined the prevalence of malnutrition in 489 older adults based on the inclusion criteria for malnutrition defined as an albumin of less than $35 \mathrm{~g} / \mathrm{L}$, Body Mass Index (BMI) of less than 19, and the Mini Nutrition Assessment (MNA) score. Based on these criteria, 91\% were either malnourished or at risk for malnutrition. Malnourished subjects had an 11-day increase in hospital stay and $25 \%$ required readmissions (35).

Evidence shows that hospital readmission rates among older adults are significant (37) and may result in costly outcomes (17). Sullivan (1992) found that protein-energy undernutrition was an independent risk factor for non-elective hospital readmission within 3 months of hospital discharge in a study of 98 older adults. Of 109 discharge assessment variables analyzed, serum albumin was the best predictor for a non-elective hospital readmission (37). Friedmann and colleagues (1997) confirmed these findings when they attempted to identify the predictors of early nonelective hospital readmission in 92 nutritionally compromised Medicare patients. Nutrition risk was identified as an albumin less than $35 \mathrm{~g} / \mathrm{L}$ and weight less than or equal to $85 \%$ of ideal body weight. Weight loss within 6 months, total lymphocyte count, vomiting, diarrhea, and poor appetite were some of the other considerations. 
Twenty-six percent of the patients were readmitted and serum albumin was the only significant variable that related to readmission (43).

Chima and associates (1997) studied the relationship between nutrition status and length of hospital stay, costs, and discharge status. There were 56 subjects in the at nutrition risk group and 117 subjects in the not at risk group. Although no significant difference in readmission rates was found, length of stay was significantly higher in the at nutrition risk group compared to those not at risk. Mean hospitalization cost was significantly higher in the at nutrition risk group, $\$ 6,196$ compared to $\$ 4,563$. The at risk group was less likely to be discharged home with self-care and was significantly more likely to use home health services (38).

\section{Nutrition Status at Discharge}

Ryan (1990) studied the relationship between nutrition risk and hospital readmission rates. Graduate gerontological nursing students studied 35 discharged Medicare patients. Lack of services, such as nutrition, and the possible impact on readmission rates within 15 days of hospital discharge, along with 15 other nutrition related variables were examined. Twenty-six patients were discharged home on modified diets. Of those patients, only 7 had a diet instruction at discharge. All patients were discharged home on medications, yet, no documentation existed stating nutrient-drug interaction educations were provided. Of the $82 \%$ of patients discharged home, only $28 \%$ received referrals for home health services (42).

Another study of malnourished patients found that although they received more nutrition care while in the hospital, lack of post discharge nutritional care existed (44). Only small percentage of malnourished patients received this service. It 
was concluded that both inpatient and outpatient nutrition care must be well coordinated to alleviate malnutrition and avoid readmission (44).

\section{Community Services}

With the change in healthcare over the past two decades, the demand to decrease length of hospital stay, and its subsequent ramifications, there is an increased need for more community programs and services to help older adults recover, maintain independence, and avoid readmission and/or institutionalization. Homebound older adults are often the most frail and undernourished group served by the U.S. healthcare system (33). According to the Administration on Aging, approximately $14 \%$ of older adults have difficulty with activities of daily living (ADLs), and $21 \%$ have difficulty with instrumental activities of daily living (IADLs) (1). Other factors that increase the risk of poor nutritional status include depression, poor dentition, being homebound, living alone, polypharmacolgy, and no regular cooked meals (45). The community programs that provide nutrition services, either indirectly or directly, vary widely across the country to help older adults in remain within their community (46). Many states are moving toward providing more home and community based services.

The Older American Act (OAA) Nutrition Program is the largest federally funded program that serves older adults within the community (47). Home delivered meals for the frail homebound are crucial in providing nourishment to vulnerable older adults (47). This OAA Nutrition Program has been effective in improving nutritional status (48). 
About $45 \%$ of home delivered meal participants heard about the Nutrition Program from hospitals or community based organizations. Unfortunately, waiting lists are common and can last from 2 to 3 months (49). Further, this Nutrition Program reaches only about $7 \%$ of older adults overall, including $20 \%$ of the nation's poorest $(47,50)$. For ambulatory older adults, congregate dining centers provide access to nutritious meals and other nutrition services (47). Congregate dining centers also provide linkages to other home and community based services (47). They promote socialization to decrease isolation, which is common among older adults. The Food Stamp Program, another federally funded program, reaches only $13 \%-35 \%$ of eligible older adults (51).

The statewide Community Care for the Elderly Program administered by the Florida Department of Elder Affairs, provides services such as transportation, home modifications and repairs, homemaking assistance, and Serving Health Insurance Needs of Elders (SHINE), many of which relate indirectly to nutritional status (47). Community programs need to expand to avoid early institutionalization of older adults, to help them maintain their independence, and to reduce Medicare and Medicaid costs. 


\section{References}

1. Administration on Aging. Profile of Older Americans: 2000. Available at: http://www.aoa.gov/aoa/stats/profile/default.htm Accessed April, 18, 2001

2. Administration on Aging. Aging into the $21^{\text {st }}$ Century. Available at: http://www.aoa.dhhs.gov/aoa/stats/aging21/demography.html Accessed February 3, 2001.

3. Kosecoff J, Kahn K, Rogers W, Reinisch E, Sherwood M, Rubenstein L, Draper $\mathrm{D}$, Roth $\mathrm{C}$, Chew C, Brook R. The prospective payment system and the impairment at discharge: the "quicker and sicker" story revised. JAMA. 1990;264:1980-1983.

4. Rogers W, Draper D, Kahn K, Keeler E, Rubenstein L. Kosecoff J, Brook R. Quality of care before and after implementation of the DRG-based prospective payment system, a summary of effects. JAMA. 1990;254:1989-1994.

5. Wayman C. Hospital-based nursing case management role clarification. Nurs Case Manag. 1999;4:236-241.

6. Pichitpornchai $\mathrm{W}$, Street A, Boontong T. Discharge planning and transitional care: issues in Thai nursing. Int J Nurs Stud. 1999;36:355-362.

7. Nazarko L. Improving hospital discharge arrangements for older people. Nurs Stan. 1997;11:44-47.

8. Boling $\mathrm{P}$. The value of targeted case management during transitional care. JAMA. 1999;281:656-657.

9. Fink A, Li Siu A, Brook R, Park P, Solomon D. Assuring the quality of health care for older persons: an expert panel's priorities. JAMA. 1987;258:1905-1908.

10. Nazarko L. Improving discharge: the role of the discharge co-ordinator. Nurs Stan. 1998;12:35-37 
11. Kennedy L, Neidlinger S, Scroggins K. Effective comprehensive discharge planning for hospitalized elderly. Gerontologist. 1987;27:577-580.

12. Naylor MD. Comprehensive discharge planning for hospitalized elderly: a pilot study. Nurs Res. 1990; 39:156-161.

13. Naylor M, Brooten D, Jones R, Lavisso-Mourey R, Mezey M, Pauly M. Comprehensive discharge planning for the hospitalized elderly, a randomized clinical trial. Ann Intern Med. 1994;120:999-1006.

14. Naylor MD, Brooten D, Campbell R, Jacobsen BS, Mezey MD, Pauly MV, Schwartz JS. Comprehensive discharge planning and home follow-up of hospitalized elders, a randomized clinical trial. JAMA. 1999;281:613-620.

15. Vinson JM, Rich MW, Sperry JC, Shah AS, McNamara T. Early readmission of elderly patients with congestive heart failure. J Am Geriatr Soc. 1990;39:10451046.

16. Marcantonio ER, McKean S, Goldfinger M, Kleefield S, Yurkofsky M, Brennan TA. Factors associated with unplanned hospital readmission among patients 65 years of age and older in a Medicare managed care plan. Am J Med. 1999;107:1317.

17. Zook CJ, Savickis SF, Moore FD. Repeated hospitalization for the same disease: a multiplier of national health costs. Milbank Mem Fund Q. 1980;58:454-471.

18. Guttman R. Case management of the frail elderly in the community. Clin Nurse Spec. 1999;13:174-178.

19. Ramey M, Daniels S. Case mangers in the hospital workplace: a light-hearted view at century's end. TCM. 2000:55-58.

20. Elliott F. The role of the case manager. Natl Med Leg J. 1992;3:6-7.

21. Mullahy C. The effective Integration of utilization and case management. TCM. 2000:53-56. 
22. Landefeld CS, Palmer RM, Kresevic DM, Fortinsky RH, Kowal J. A randomized trail of care in a hospital medical unit especially designed to improve functional outcomes of acutely ill older patients. N Engl J Med. 1995;332:1338-1344.

23. Administration on Aging. The Administration on Aging and the Older Americans Act. Available at: http://www.aoa.gov/aoa/pages/aoafact.html Accessed March 5, 2001

24. Fink A, Siu A, Brook R, Park R, Solomon D. Assuring the quality of health care for older persons: an expert panel's priorities. JAMA. 1987;258:1905-1908.

25. Hofmeyer A, Claire J. The role of the hospital liason nurse in effective discharge planning for older people: perspectives of discharge planners. Contemp Nurse. 1999;8:99-105.

26. Nolan M, Harris A, Kufta A, Opfer N, Turner H. Preparing nurses for the acute care case manager role: educational needs identified by existing case managers. $J$ Contin Educ. 1998;29:130-134.

27. Czerenda J, Best L. Tying it all together: integrating a hospital-based health care system through case management education. J Case Management. 1994;3:69-73.

28. Jones D, Lester C. Hospital care and discharge patients' and carers' opinions. Age and Aging. 1994;23:91-98.

29. Bull M, Hansen H, Gross C. Predictors of elder and family caregiver satisfaction with discharge planning. J Cardiovasc Nurs. 2000:76-87.

30. Dudas V, Bookwalter T, Kerr K, Pantilat S. The impact of follow-up telephone calls to patients after hospitalization. Am J Med. 2001;111:26S-30S.

31. Weddle DO, Fanelli-Kuczmarski M. Position of the American Dietetic Association: nutrition, aging, and the continuum of care. J Am Diet Assoc. 2000;100:580-596.

32. Nutrition Screening Initiative. Nutrition Interventions Manual for Professionals Caring for Older Americans. Washington, DC: Greer, Margolis, Mitchell, Grunwald and Associates, Inc. 1992. 
33. Institute of Medicine. Committee on Nutrition Services for Medicare Beneficiaries. The Role of Nutrition in Maintaining Health in the Nation's Elderly: Evaluating Coverage of Nutrition Services for the Medicare Population. Washington, DC: National Academy Press: 1999.

34. Practicing report of the American Dietetic Association. Home-care: an emerging practice area for dietetics. J Am Diet Assoc. 1999;99:1453-1459.

35. Thomas D, Zdrowski C, Wilson M, Conrigh K, Lewis C, Tariq S. Malnutrition in subacute care. Am J Clin Nutr. 2002;75:308-313.

36. Sullivan DH, Walls RC. Protein-Energy Undernutrition and the Risk of Mortality Within Six years of hospital discharge. J Am Coll Nutr. 1998; 17:571-578.

37. Sullivan DH. Risk factors for early hospital readmission in a select population of geriatric rehabilitation patients: the significance of nutritional status. J Am Geriatr Soc. 1992; 40:792-798.

38. Chima CS, Barco K, Dewitt MLA, Maeda M, Teran JC, Mullen KD. Relationship of nutritional status to length of stay, hospital costs, and discharge status of patients hospitalized in the medicine service. J Am Diet Assoc. 1997:975-978.

39. Gallagher-Allred C, Coble Voss A, Finn S, McCamish M. Malnutrition and clinical outcomes: the case for medical nutrition therapy. $J$ Am Diet Assoc. 1996;96:361-366.

40. Brugler L, Diprinzio M, Berstein L. The five-year evolution of a malnutrition treatment program in a community hospital. J Quality Improvement. 1999:191206.

41. Compher C, Kim J, Bader J. Nutrition requirements of an aging population with emphasis on subacute care patients. AACN Clin Issues. 1998;9:441-450.

42. Ryan C. Nutrition identified as a risk factor for elder Medicare Patients' hospital readmission. J Nutr Elder. 1990;9:81-87. 
43. Friedmann J, Jensen G, Smickiklas-Wright H, McCamish M. Predicting early nonelective hospital readmission in nutritionally compromised older adults. Am J Clin Nutr. 1997;65:1714-1720.

44. Weddle DO, Schmeisser D, Barnish M, Kamath S. Inpatient and post-discharge course of malnourished patient. J Am Diet Assoc. 1991;91:307-311.

45. Rafferty S. Age old nutrition problems. The World of Irish Nursing. 2000:34-35.

46. Elder Affairs Programs and Services. Available at: www.7.myflorida.com/doea/healthfamily/learn/elderpr.../doeaprogramsandservice s.htm accessed April 18, 2001.

47. Wellman N, Rosenzweig L, Lloyd J. Thirty years of the Older Americans Nutrition Program. J Am Diet Assoc. 2002;102:348-350.

48. McKay D, Wilson J, Martin C, Lundberg Bourdet K, Blumberg J, Holay S. The impact of home-delivered meals on elderly patients. Care Management. 2000;3236.

49. Executive Summary: Serving elders at risk. Available at: www.aoa.gov/aoa/nutreval/execsum.html Accessed March 9, 2001.

50. Millen B, Ohls J, Ponza M, McCool A. The Elderly Nutrition Program: an effective national framework for preventive nutrition interventions. $J$ Am Diet Assoc. 2002;102:234-240.

51. Chernoff R. Geriatric Nutrition: The Health Professional's Handbook. Second Edition. Gaithersburg, MD. Aspen Publishers, Inc.1999. 


\section{Chapter III ${ }^{1}$}

Hospital Discharge Planning in the Provision of Food and Nutrition Services for Older Adults Post Discharge

\section{Introduction}

As we moved into the $21^{\text {st }}$ century, the aging of America and the issues surrounding the adequacy of our healthcare system have become national concerns. By 2010 , there will be 39.4 million older adults, aged 65 and older. The number of older adults is expected to almost double to 75 million by 2050(1). Based on these numbers, an effective and comprehensive healthcare system is needed to ensure their safety, wellbeing, and quality of life.

The Prospective Payment System (PPS), which began in the 1980s, pays hospitals amounts based on flat rates per admission based on approximately 470 diagnosis related groups (DRGs)(2). This system offers incentives in reducing length of stay and substituting lower costs services for more expensive ones. Evidence suggests that since PPS implementation, individuals are leaving the hospital "quicker and sicker" (2). Currently, healthcare costs are overwhelming and may inhibit older adults from obtaining the necessary comprehensive care. Many older adults have financial hardships, multiple chronic medical conditions, functional limitations, and feel that they have no one to turn to for help $(1,3)$. Over one quarter of older adults rated their health as fair to poor (1).

\footnotetext{
${ }^{1}$ This chapter will be submitted as a manuscript to the Journal of the American Dietetic Association.
} 
The purpose of hospital discharge planning is to provide a continuous care post discharge while, at the same time, staying within DRG cost containment parameters by decreasing length of stay. The need for improved discharge planning is well recognized (4). Inadequate discharge planning methods that include poor interprofessional cooperation, poor documentation, inadequate patient consultation, and communication have been reported for over 25 years (5).

Hospital readmissions are common in older adults and account for $25 \%$ of Medicare expenditures (6). Readmissions have been linked to problems in discharge planning (7). Patient and caregiver satisfaction is an important outcome measure of discharge planning as adherence to medical plans may decrease readmission rates (8). Readmissions are $24 \%-55 \%$ higher in cost compared to the first admission (7). Financial implications of early discharge to Medicare beneficiaries include frequent emergency room visits, acute care visits, and home care nursing visits (9). It has been estimated that a $20 \%$ reduction in readmissions could save over $\$ 11$ billion dollars in hospital costs $(10)$.

A strategic overview of discharge planning has been defined as one that promotes health, reduces lost bed days and readmission rates, reduces morbidity, and overseas efficient and effective care for those who are ill (11). All must be accomplished within the DRG guidelines and strict time frames. Comprehensive discharge planning specializing in the needs of older adults has had positive outcomes in reducing length of stay and readmission rates $(12,13)$. However, comprehensive discharge planning is uncommon. Often discharge planning is only a part of the many job responsibilities held by case managers (14). 
Multidisciplinary involvement is considered crucial in providing quality care (15). In a study by Landlefeld and associates, a multidisciplinary approach significantly decreased the prevalence of functional decline in hospitalized, medically ill, older adult patients (15). Yet, adequate communication can be a problem. In a study by Pichitpornchi and colleagues, communication between the physician and other members of the team were insufficient and casual in nature (16). Written communication can also be a barrier to effective discharge planning. Nursing documentation that rarely details a patient's previous level of functioning or home circumstances can present problems in the decision making process (11). One study showed that hospital case managers felt frustrated facilitating post discharge care (17). Community case managers were often physically and emotionally drained, as older adult needs extended far beyond the resources available (18).

Scientific evidence shows that sound nutrition is essential for health, selfsufficiency and quality of life for older adults (19). Diseases associated with dietary imbalances rank among the leading causes of illness and death in the United States (20). Further, malnutrition continues to be a problem for this population group (20-26). Malnutrition is associated with negative health outcomes, such as slower healing rates, increased risk for medical and surgical complications, delayed recovery from physical traumas, increased length of stay, increased readmission rates and mortality (20-26). Some of the reasons for malnutrition include disease states and social conditions that prevent older adults from purchasing, preparing, or consuming food (25).

Research suggests that older adults living alone do not consume adequate amounts of food (27). Approximately $40 \%$ of older adults have inappropriate dietary 
intake of 3 or more nutrients (20). Over $85 \%$ of older adults living in the community have one or more chronic conditions that could be improved by proper nutrition (28). Studies have shown that the Older Americans Act Nutrition Program has improved nutritional status $(29,30)$. Community nutrition programs and related services exist to help older adults maintain their independence and quality of life $(29,30)$. Still, 2 of the 9 million older adults living alone feel that they have no one to turn to for assistance (3).

The purpose of this study was to examine the hospital discharge planning process and the provision of food and nutrition services post discharge.

\section{Methods}

\section{$\underline{\text { Subjects }}$}

A list of case management directors in 11 South Florida hospitals located in Palm Beach, Broward and Miami-Dade counties was gathered. Hospitals in South Florida were chosen because the state of Florida ranks first in the percentage of its population 65 years of age and older (1). Data collection occurred between October and December 2002 after approval by the Florida International University Institutional Review Board (Appendix 1).

Each of the 11 case management directors was contacted via phone and/or email to explain the purpose of the study. At that time, the director provided the number of case management personnel in their hospital and made an appointment to meet with the case managers as a group to distribute the questionnaires.

In 8 hospitals, a verbal, on site explanation about the study was provided to the groups. In 3 of the hospitals, the study was explained to the directors by phone and the 
questionnaires were faxed. An informed consent letter, that explained that there were no identifiable risks or benefits to participating in the study and that confidentiality would be strictly guarded, accompanied each questionnaire. Names and numbers of the major professor and the chairperson of Florida International University's Institutional Review Board were included in the letter. Most of the questionnaires were completed while the principle investigator was on site. Some questionnaires were mailed or faxed back upon completion. Of the 95 questionnaires distributed, 84 were completed, yielding an $88 \%$ response rate.

As an incentive, all participants received a small, health-promoting gift, a step counter from the Steps to Healthy Aging project at the National Resource Policy Center on Nutrition and Aging. Step Counter brochures along with ordering information were provided. Participants were encouraged to use the step counter information themselves and to share about it with their older adult patients to encourage healthy aging.

Questionnaire

The 3-page questionnaire (Appendix 2) included 86 questions and sections for comments. The format was carefully designed to take approximately 10-15 minutes to complete. Individuals in the aging network reviewed drafts of the questionnaire for content purposes. It was then piloted by 3 case managers in a South Florida hospital that was not part of the sample. They evaluated it for content, clarity of language, and meaning. It was then modified slightly before distribution at the 11 South Florida hospitals.

The first page of the questionnaire contained 12 questions with multiple choice options that examined demographics, credentials and certifications, case load, time spent 
discharge planning, and perceived job barriers. The second page included 4 sections, with 5-point likert-type questions. Section "A" included 8 questions that asked how important various healthcare professionals were in the discharge planning process. Those listed were the medical doctor, occupational therapist, pharmacist, physical therapist, registered dietitian, registered nurse, social worker, and speech therapist. Choices included "very important," "important," "neutral," "slightly important," and "not important." Section " $\mathrm{B}$ " examined the percent time spent consulting each of the 8 healthcare professionals. Options ranged from "75-100\%," "50-74\%," "25-49\%," "1-24\%," and "0\%." Fourteen factors that influenced the nutrition care plan such as "driving ability," "modified diet," "lives alone," "vision difficulty," and "underweight" were listed in "Section C." Fourteen medical conditions that influenced the nutrition care plan post discharge such as, "AIDS," "diabetes," "stroke," "home tube feeding" and "pressure ulcers," were addressed in Section "D." Likert answer options for Sections "C" and "D" were "strongly influence," “influence," "neutral," "slightly influence," and "no influence."

The third page of the questionnaire included 3 sections. Sections "E" and "F" each had lists of the same 12 community services. Some of the options listed included "adult day care," "congregate meals," "shopping assistance," "meals on wheels," and "outpatient dietitians." Section "E" asked if the case managers felt that they had "adequate information" about available community resources, while section "F" asked if they felt that this information was "readily available." Answer options were "yes," "no," and "unsure."

Section "G" provided 6 case scenarios. They were " a patient identified as malnourished with no insurance," "a mentally appropriate patient who cannot drive and 
does not have friends/family in the area," "a patient on TPN," "a patient on tube feeding," "a patient on a pureed diet with thick liquids," and "a patient re-admitted twice in your facility within the same month." Multiple options were possible which included contacting "Elder Helpline," "home delivered meals," "home health care agency," "outpatient clinic/classes," "inpatient dietitian," "outpatient dietitian," and "other."

$\underline{\text { Data Analysis }}$

Data from the 85 questionnaires were entered into a Microsoft Excel spreadsheet for organizational purposes. Data were then transferred to the SPSS for Windows program, version 11.5, for analysis. Descriptive statistics such as frequencies and percentages were used.

\section{Results}

\section{Characteristics of discharge planning professionals}

Characteristics of the 84 discharge planning professionals are summarized in Table 1 . They were mostly female (98\%), between the ages of $40-49(41 \%)$, White nonHispanic (59\%), and registered nurses (61\%). Other discharge planning professionals included licensed social workers $(8 \%)$ and licensed practical nurses $(6 \%)$. There were no registered dietitians that assumed discharge planning roles. Over $70 \%$ were classified as "case managers" while 5\% were classified as "discharge planners" according to job titles defined by each of the 11 hospital Human Resource Departments. Over 35\% had Bachelor's degrees, 25\% had Associates degrees, 17\% had diplomas, and 10\% had Master's degrees. About $15 \%$ had specialized case management/discharge planning certifications; $13 \%$ were certified case managers (CCM) and 5\% were certified 
professional utilization review (CPUR) case managers. While 22\% had "other" types of certifications, $61 \%$ had no certifications. Most had previous preparation but were fairly new in their current positions, with over 50\% having 0-2 years discharge planning in their current facilities.

Time spent and perceived barriers in discharge planning

Table 2 describes the time spent and perceived barriers to discharge planning. Most provided discharge planning to $20-39$ patients per day. Approximately $74 \%$ of the sample spent either $25-50 \%$ of their time or greater than $75 \%$ of their time discharge planning. Almost all (98\%) reported job barriers. The greatest barrier was an excessive patient load (53\%).

Healthcare professionals deemed important in the discharge planning process

Table 3 presents the perceptions of discharge planning professionals regarding the importance of other healthcare professionals in the discharge planning process. Eighty two percent considered the medical doctor as "very important," $74 \%$ the registered nurse, $65 \%$ social worker, $59 \%$ the physical therapist, $31 \%$ the pharmacist, $28 \%$ the occupational therapist, $27 \%$ the registered dietitian, and $27 \%$ the speech therapist. Eleven percent considered the registered dietitian "slightly important," while 5\% said they were "not important."

Time spent consulting other healthcare professionals in the discharge planning process

Forty six percent or more of discharge planning professionals consulted the medical doctor $(68 \%)$, registered nurse $(57 \%)$, and social worker $(46 \%)$ between 75 $100 \%$ of the time (Table 4 ). The physical therapist (42\%) was frequently consulted 50 $74 \%$ of the time. The occupational therapist $(30 \%)$ and registered dietitian $(33 \%)$ were 
frequently consulted between $25-49 \%$ of the time. The pharmacist (38\%) and speech therapist (34\%) were frequently consulted between $1-24 \%$ of the time. Almost half of discharge planning professionals never consulted registered dietitians or consulted them fewer than $24 \%$ of the time.

Nutrition related medical conditions, factors, and resources affecting post discharge care

Fourteen medical conditions were listed in the questionnaire. Discharge planning professionals ranked the level of importance of each condition. Conditions included AIDS, cancer, cardiac condition, depression, diabetes, HIV, home TPN, home tube feeding, hypertension, intestinal problems, post operation, pressure ulcers, renal failure, and stroke. Greater than $95 \%$ reported that all conditions "strongly influenced" the post discharge care plan. The first half of Table 5 includes the 14 factors that "strongly influenced" the post discharge care plan. Greater than $84 \%$ said all 14 factors "strongly influenced" the post discharge care plan. Discharge planning professionals felt that both medical conditions and factors listed either "strongly influenced" or "influenced" the post discharge care plan. None of them selected "neutral," "slightly influence" or "no influence" as options.

The second half of Table 5 lists 12 community services readily available to meet post discharge needs. Some of these services directly or indirectly provide food and nutrition services to older adults. Of those listed, only 4 services were considered readily available by more than half of discharge planning professionals. Less than $50 \%$ thought that 8 services were readily available. These services included food stamps $(48 \%)$, congregate meals (43\%), shopping assistance (40\%), home modifications/repairs (18\%), Serving Health Insurance Needs of Elders (SHINE) (18\%), outpatient registered 
dietitians (10\%), Farmers Market Coupon Program (6\%), and volunteer ophthalmologists $(4 \%)$.

\section{$\underline{\text { Case Scenarios }}$}

The final series of questions, not presented in a table, included 6 nutrition related case scenarios. In the first case scenario of "a malnourished patient with no insurance," $48 \%$ would contact the Elder Helpline, $46 \%$ home delivered meals, $34 \%$ home health care agency, $24 \%$ outpatient clinics/classes, $36 \%$ inpatient dietitian, $18 \%$ outpatient dietitian, $7 \%$ would utilize "other" methods/strategies. For "A mentally appropriate patient who cannot drive and does not have friends/family in the area," $43 \%$ would contact the Elder Helpline, 76\% home delivered meals, $43 \%$ home health care agency, $12 \%$ outpatient clinics/classes, $22 \%$ inpatient dietitian, $11 \%$ outpatient dietitian, and $6 \%$ "other." For "a patient on TPN," 11\% would contact the Elder Helpline, $8 \%$ home delivered meals, $89 \%$ home health care agency, $10 \%$ outpatient clinics/classes, $30 \%$ inpatient dietitian, $22 \%$ outpatient dietitian, and $4 \%$ other. In the fourth case scenario, "a patient on tube feeding," $7 \%$ would contact the Elder Helpline, $7 \%$ home delivered meals, $92 \%$ home health care agency, $10 \%$ outpatient clinics/classes, $29 \%$ inpatient dietitian, $25 \%$ outpatient dietitian, and $10 \%$ "other." For "a patient on a pureed diet with thick liquids," $10 \%$ would contact the Elder Helpline, 18\% home delivered meals, $68 \%$ home health care agency, $8 \%$ outpatient clinics/classes, $37 \%$ inpatient dietitian, $25 \%$ outpatient dietitian, and 5\% "other." In the final case scenario, "a patient re-admitted twice in your facility within the same month," $36 \%$ would contact the Elder Helpline, $25 \%$ home delivered meals, $65 \%$ home health care agency, $18 \%$ outpatient clinics/classes, $37 \%$ inpatient dietitian, $12 \%$ outpatient dietitian, and $24 \%$ "other." 


\section{Discussion}

$\underline{\text { Characteristics of discharge planning professionals }}$

The results of this study indicated that those responsible for discharge planning were primarily female, registered nurses, and classified as case managers. These 3 characteristics were consistent with the literature (31). Nursing case management has been in existence for many years and has been recognized as a professional avenue for nurses $(32,33)$. However, nursing case management continues to evolve. The role continues to be ill-defined and has been noted for its ambiguity and confusion (32).

In this study, the sample size of 84 discharge planning professionals in 11 South Florida hospitals was substantial in comparison to another study (31). One published study that examined discharge planning professionals included 20 subjects (31). There appears to be more research focusing on the discharge planning process and less on those who conduct discharge planning.

Discharge planning training

Sixty one percent of the sample had previous preparation in discharge planning. It was provided in a variety of ways: "on the job training," "previous experience," "internship," "seminars," and "CEUs" (continuing education units). According to one study, little literature exists on how to best prepare nurses for case management roles (31). Although few having had formal preparation, discharge planning is frequently an added responsibility to an already full case load of a nurse or social worker (34). It is interesting that educational topics most requested by nurse case managers were community resources and discharge planning (31). 
Time spent and barriers to discharge planning

Approximately $37 \%$ of the discharge planning professionals spent between 25 $50 \%$ of their time discharge planning. These results are consistent with findings of Ramey and Daniels in that they reported case managers spent approximately $30 \%$ of their day discharge planning, with the remaining $70 \%$ on a multitude of other tasks (14). Almost $50 \%$ of discharge planning professionals in our study reported that they had too many daily responsibilities.

While $98 \%$ reported job barriers, an excessive patient load was the most commonly reported barrier. With cost containment efforts and subsequent decreases in length of stay, there is even less time for discharge planning professionals to get to know their patients and plan properly for discharge (11). Considerable time with families was also reported as a job barrier. Time is needed in implementing comprehensive discharge plans. While an in depth discharge planning process is often needed to specifically address the needs of older adults, it is uncommon.

\section{Multidisciplinary teams}

Almost $60 \%$ of discharge planning professionals deemed the medical doctor, registered nurse, social worker, and physical therapist as "very important" to the discharge planning process, but fewer than $31 \%$ said the pharmacist, occupational therapist, registered dietitian, and speech therapist were "very important." Over $15 \%$ of discharge planning professionals considered the registered dietitian to be either "slightly important," or "not important."

While $46 \%$ or more of discharge planning professionals consulted the medical doctor, registered nurse and social worker $75-100 \%$ of the time, only $4 \%$ consulted 
registered dietitians $75-100 \%$ of the time. Almost half of the discharge planning professionals never consulted registered dietitians or consulted them fewer than $24 \%$ of the time. In comparison, less than 5\% never consulted medical doctors and registered nurses or consulted them fewer than $24 \%$ of the time.

For the past 25 years, inadequate discharge planning has been linked to poor interprofessional cooperation (5). Older adults need an array of experienced healthcare professionals to be involved in their care. Quality of life is enhanced when mental health, oral health, medication use, food choices, economic situations, medical conditions, and functional status are addressed (20). In previous studies, comprehensive discharge planning which focused on all disciplines had positive outcomes $(12,13)$. Further, it is the responsibility of the multidisciplinary team to gain knowledge of community resources, within their respective fields, in order to better serve discharge planning professionals. $\underline{\text { Nutrition related medical conditions, factors and case scenarios }}$

The majority of discharge planning professionals thought that nutrition related medical conditions and factors strongly influenced the discharge plan. Still gaps exist as over $30 \%$ thought that registered dietitians were not important and $45 \%$ consulted them infrequently, if at all.

Of the 6 nutritionally related case scenarios presented, less than $40 \%$ of discharge planning professionals would contact the inpatient dietitian and less than $25 \%$ would refer to an outpatient dietitian. Only $10 \%$ of discharge planning professionals had readily available information about outpatient dietitians despite the passage of the Medicare Medical Nutrition Therapy (MNT) Bill (H.R. 5661) (35). Registered dietitians need to be more involved in the discharge planning process as nutrition related problems affect 
many older adults who are returning home. Up to $40 \%$ of frail, homebound older adults suffer from protein-energy malnutrition (28). Further, the registered dietitian has been recognized as the single, identifiable group of healthcare professionals with standardized and continuing education, clinical training, and national credentialing requirements necessary to provide nutrition therapy (36).

\section{Community Resources}

Scientific evidence supports nutrition as a crucial component in maintaining the health, well being, and independence of older adults (28). Although most discharge planning professionals reported nutrition related factors as strongly influencing the discharge plan, few had readily available information about community resources. Less than $50 \%$ did not know 8 of the 12 services which included volunteer ophthalmologists, Farmers' Market Coupon Program, outpatient registered dietitians, Serving Health Insurance Needs of Elders (SHINE), home modifications/repairs, shopping assistance, congregate meals, and food stamps. Yet, all of these services are designed to serve older adults and may directly or indirectly provide access to food and nutrition therapy. Some services, including home delivered meals, are a part of the Older Americans Act Nutrition Program, the largest federally funded program that targets older adults living in the community (37). Most discharge planning professionals believed that home delivered meals were readily available. Still, over $41 \%$ of these programs have waiting lists (29).

Many older adults have difficulty with cooking, shopping, and walking, all which have serious implications on nutritional status (37). It is estimated that $15 \%$ of older adults living in the community have nutrient deficiencies (2). In the United States, 2 of the 9 million older adults living alone believe that there is no one for them to turn to for 
help (3). In the 6 case scenarios presented in this study, there was an array of strategies to provide nutrition care post discharge. A universal approach was non-existent in solving nutrition related problems.

\section{$\underline{\text { Limitations }}$}

This study had some limitations. Although the sample size was substantial, this study was conducted in Florida. Therefore, national conclusions may not be warranted. The 11 hospitals were owned by one health care system. It is possible that this health care system's approach to discharge planning is not represented. Therefore, conclusions can not be made about the discharge planning process for hospitals owned by other healthcare systems.

Since the 11 hospitals were located in 3 South Florida counties, it is possible that these hospital populations varied in age and economic status in comparison to those in other parts of Florida, and in other states. Thus the gaps in perceived knowledge of and readily available community resources vary considerably. 


\section{Summary and Conclusions}

This descriptive study examined whether discharge planning ensures that food and nutrition services are provided to older adults following hospital discharge. Of the 95 questionnaires distributed to discharge planning professionals in 11 South Florida hospitals, 84 were completed, yielding an $88 \%$ response rate. The majority of discharge planning professionals were female (98\%), White, non-Hispanic (59\%), Registered Nurses (61\%), ages $40-49$ years $(41 \%)$, with previous discharge planning preparation (61\%). Most had "case manager" as their job title. The nursing case manager role continues to evolve but remains ill defined. While an in depth discharge planning process is often needed to specifically address the needs of older adults, it is uncommon.

Almost all reported some job barriers including excessive patient loads, too many daily responsibilities, limited community services, and difficulty coordinating discharge services.

Almost $60 \%$ of discharge planning professionals deemed the medical doctor, nurse, social worker, and physical therapist as "very important" to the discharge planning process, but fewer than $31 \%$ said the pharmacist, occupational therapist, registered dietitian, and speech therapist were "very important."

While $46 \%$ or more of discharge planning professionals consulted the medical doctor, nurse and social worker $75-100 \%$ of the time, only $4 \%$ consulted registered dietitians $75-100 \%$ of the time. Almost half of the discharge planning professionals never consulted registered dietitians or consulted them $24 \%$ or less of the time. In comparison, less than $5 \%$ never consulted medical doctors and registered nurses or consulted them $24 \%$ or less of the time. For the past 25 years, poor interprofessional cooperation has 
been linked to inadequate discharge planning. Older adults are known to need an array of experienced healthcare professionals for comprehensive care. Comprehensive discharge planning which involved all disciplines had positive outcomes.

Over $84 \%$ of respondents said nutrition-related medical conditions and factors, eg, swallowing disability, poor appetite, lives alone, underweight, walking difficulty, modified diet, poor dentition, etc., "strongly influenced" the discharge care plan. While nutrition related medical conditions and factors "strongly influenced" the discharge plan, only $27 \%$ of discharge planning professionals considered dietitians "very important" in discharge planning. Many did not have readily available information about nutritionrelated community resources, eg, congregate meals, food stamps, and outpatient registered dietitians.

There were varying strategies, little consistency, and no universal approaches in meeting the food and nutrition needs described in 6 case scenarios. Issues regarding malnutrition, modified diet, enteral and parenteral nutrition, isolation, and readmission were addressed in the case scenarios. Contacting the Elder Helpline, home delivered meal program, home health agencies, inpatient and outpatient dietitians, and outpatient clinic/classes were listed as options. Others have written that it is the responsibility of the multidisciplinary team to gain knowledge of community resources, within their respective fields, in order to better serve discharge planning professionals.

It is concluded that more communication is needed between hospitals and community based programs to provide better comprehensive care to older adults. While discharge planning professionals were concerned about the nutritionally related medical conditions and factors of their patients, they were unaware of the majority of food and 
nutrition related community resources. This study supports earlier recommendations that in-service education about community resources be provided to discharge planning professionals and others members of multidisciplinary teams in hospitals. This study's findings suggest that inpatient hospital dietitians need to become more involved in the discharge planning process to improve the nutritional status of many of their patients who are discharged malnourished or at nutrition risk. Outpatient dietitians were among the least utilized community resources, despite the recent approval of Medicare payment for nutrition therapy. Outpatient dietitians, including those in private practice, are encouraged to communicate with hospital discharge planning professionals regarding the availability of their services. Nutritionists and dietitians in the aging network are likewise encouraged to reach out to community hospitals to help discharge planning professionals recognize those older adults who would benefit from participation in their community food and nutrition services. Assuring that older adults are provided with the food and nutrition services available in the community is likely to reduce readmission rates, length of stays, and early institutionalization, maintain quality of life and independence, and minimize health care expenditures. 


\section{Applications}

The discharge planning process has existed for many years and has been widely critiqued. This study showed that $98 \%$ of discharge planning respondents reported a myriad of perceived job barriers. As the population of older adults continues to grow, they will require improved and more effective discharge planning to decrease recidivism, Medicare/Medicaid expenditures, and early institutionalization. Comprehensive discharge planning, specifically tailored to older adults, and one that includes all healthcare disciplines, is fundamental.

Discharge planning professionals had limited knowledge of community programs and services. Since many older adults rely upon community resources to remain independent and functional, it is imperative that information about programs and services be adequately provided to discharge planning professionals. Nutrition-related community organizations should provide continual inservices to discharge planning professionals and to hospital dietitians to help them learn about resources and referral procedures. This would provide them with the tools for comprehensive discharge planning. Community programs and services must continue to be improved, strengthened, and expanded to serve older adults adequately.

Inpatient registered dietitians need to become more proactive in the discharge planning process. They must serve as a liaison to discharge planning professionals and actively seek information about nutrition related community resources, to help prevent malnutrition and associated complications, common among recently discharged older adults. 
Outpatient registered dietitians need to develop better marketing strategies in promoting their nutrition services to older adults. It is recommended that they build relationships and work closely with hospital discharge planning professionals. Better interdisciplinary communication, especially between the hospital and community, provides a holistic approach in promoting wellness in older adults. 


\section{References}

1. Administration on Aging. Profile of Older Americans: 2000. Available at: http://www.aoa.gov/aoa/stats/profile/default.htm Accessed April, 18, 2001.

2. Kosecoff J, Kahn K, Rogers W, Reinisch E, Sherwood M, Rubenstein L, Draper $\mathrm{D}$, Roth $\mathrm{C}$, Chew $\mathrm{C}$, Brook R. The prospective payment system and the impairment at discharge: the "quicker and sicker" story revised. JAMA. 1990;264:1980-1983.

3. Administration on Aging. The Administration on Aging and the Older Americans Act. Available at: http://www.aoa.gov/aoa/pages/aoafact.html Accessed March 5, 2001.

4. Boling $\mathrm{P}$. The value of targeted case management during transitional care. JAMA. 1999;281:656-657.

5. Nazarko L. Improving hospital discharge arrangements for older people. Nurs Stan. 1997;11:44-47.

6. Vinson JM, Rich MW, Sperry JC, Shah AS, McNamara T. Early readmission of elderly patients with congestive heart failure. J Am Geriatr Soc. 1990;39:10451046.

7. Marcantonio ER, McKean S, Goldfinger M, Kleefield S, Yurkofsky M, Brennan TA. Factors associated with unplanned hospital readmission among patients 65 years of age and older in a Medicare managed care plan. Am J Med. 1999;107:1317.

8. Bull M, Hansen H, Gross C. Predictors of elder and family caregiver satisfaction with discharge planning. $J$ Cardiovasc Nurs. 2000:76-87.

9. Naylor M, Brooten D, Jones R, Lavisso-Mourey R, Mezey M, Pauly M. Comprehensive discharge planning for the hospitalized elderly, a randomized clinical trial. Ann Intern Med. 1994;120:999-1006.

10. Zook CJ, Savickis SF, Moore FD. Repeated hospitalization for the same disease: a multiplier of national health costs. Milbank Mem Fund Q. 1980;58:454-471. 
11. Nazarko L. Improving discharge: the role of the discharge co-ordinator. Nurs Stan. 1998;12:35-37.

12. Kennedy L, Neidlinger S, Scroggins K. Effective comprehensive discharge planning for hospitalized elderly. Gerontologist. 1987;27:577-580.

13. Naylor MD, Brooten D, Campbell R, Jacobsen BS, Mezey MD, Pauly MV, Schwartz JS. Comprehensive discharge planning and home follow-up of hospitalized elders, A randomized clinical trial. JAMA. 1999;281:613-620.

14. Ramey M, Daniels S. Case mangers in the hospital workplace: a light-hearted view at century's end. TCM. 2000:55-58.

15. Landefeld CS, Palmer RM, Kresevic DM, Fortinsky RH, Kowal J. A randomized trail of care in a hospital medical unit especially designed to improve functional outcomes of acutely ill older patients. N Engl J Med. 1995;332:1338-1344.

16. Pichitpornchai W, Street A, Boontong T. Discharge planning and transitional care: issues in Thai nursing. Int J Nurs Stud. 1999;36:355-362.

17. Hofmeyer A, Claire J. The role of the hospital liason nurse in effective discharge planning for older people: perspectives of discharge planners. Contemp Nurse. 1999;8:99-105.

18. Guttman R. Case management of the frail elderly in the community. Clin Nurse Spec. 1999;13:174-178.

19. Weddle DO, Fanelli-Kuczmarski M. Position of the American Dietetic Association: nutrition, aging, and the continuum of care. J Am Diet Assoc. 2000;100:580-596.

20. Nutrition Screening Initiative. Nutrition Interventions Manual for Professionals Caring for Older Americans. Washington, DC: Greer, Margolis, Mitchell, Grunwald and Associates, Inc. 1992.

21. Thomas D, Zdrowski C, Wilson M, Conrigh K, Lewis C, Tariq S. Malnutrition in subacute care. Am J Clin Nutr. 2002;75:308-313. 
22. Sullivan DH, Walls RC. Protein-energy undernutrition and the risk of mortality within six years of hospital discharge. J Am Coll Nutr. 1998;17:571-578.

23. Sullivan DH. Risk factors for early hospital readmission in a select population of geriatric rehabilitation patients: the significance of nutritional status. $J$ Am Geriatr Soc. 1992;40:792-798.

24. Chima CS, Barco K, Dewitt MLA, Maeda M, Teran JC, Mullen KD. Relationship of nutritional status to length of stay, hospital costs, and discharge status of patients hospitalized in the medicine service. J Am Diet Assoc. 1997:975-978.

25. Gallagher-Allred C, Coble Voss A, Finn S, McCamish M. Malnutrition and clinical outcomes: the case for medical nutrition therapy. J Am Diet Assoc. 1996;96:361-366.

26. Brugler L, Diprinzio M, Berstein L. The five-year evolution of a malnutrition treatment program in a community hospital. J Quality Improvement. 1999:191206.

27. Ryan C. Nutrition identified as a risk factor for elder Medicare Patients' hospital readmission. J Nutr Elder. 1990;9:81-87.

28. Chernoff R. Geriatric Nutrition: The Health Professional's Handbook. Second Edition. Gaithersburg, MD. Aspen Publishers, Inc.1999.

29. Executive Summary: Serving Elders at Risk: The Older Americans Act Nutrition Programs-National Evaluation of the Elderly Nutrition Program, 1993-1995. Administration on Aging. Available at: www.aoa.gov/aoa/nutreval/execsum.html accessed March 9, 2001.

30. McKay D, Wilson J, Martin C, Lundberg Bourdet K, Blumberg J, Holay S. The impact of home-delivered meals on elderly patients. Care Management. 2000:2-7.

31. Nolan M, Harris A, Kufta A, Opfer N, Turner H. Preparing nurses for the acute care case manager role: educational needs identified by existing case managers. $J$ Contin Educ. 1998;29:130-134. 
32. Wayman C. Hospital-based nursing case management role clarification. Nurs Case Manag. 1999;4:236-241.

33. Forbes M. The practice of professional nurse case management. Nurs Case Manag. 1999;4:28-33.

34. Haddock KS, Collaborative discharge planning: nursing and social services. Clin Nurs Spec. 1994;8:248-252.

35. H.R.5661 Medicare, Medicaid, and SCHIP Benefits Improvement and Protection Act of 2000. SEC. 105. Coverage of medical nutrition therapy services for beneficiaries with diabetes or a renal disease. Available at:

http://thomas.loc.gov/cgi-bin/query/z?c106:H.R.5661. Accessed December 28, 2000.

35. Institute of Medicine. The Role of Nutrition in Maintaining Health in the Nation's Elderly. Evaluating Coverage of Nutrition Services for the Medicare Population. Washington, DC: National Academy Press;2000.

36. Wellman N, Rosenzweig L, Lloyd J. Thirty years of the Older Americans Nutrition Program. J Am Diet Assoc. 2002;102:348-350.

37. Rafferty S. Age old nutrition problems. The World of Irish Nursing. 2000:34-35. 
Table 1

Characteristics of discharge planning professionals $(n=84)$

\begin{tabular}{lrrr}
\hline Variable & No. & \% \\
\hline Gender $^{\mathbf{2}}$ & & \\
& Female & 81 & 97.6 \\
& Male & 2 & 2.4 \\
& Total & $\mathbf{8 3}$ & $\mathbf{1 0 0 . 0}$ \\
& & & \\
\hline Age & & & \\
& $20-29$ & 8 & 9.5 \\
& $30-39$ & 17 & 20.2 \\
& $40-49$ & 34 & 40.5 \\
& $50-59$ & 22 & 26.2 \\
$60+$ & 3 & 3.6 \\
& Total & $\mathbf{8 4}$ & $\mathbf{1 0 0 . 0}$
\end{tabular}

\section{Ethnicity ${ }^{\mathbf{a}}$}

White, non-Hispanic

$48 \quad 58.5$

Hispanic

$16 \quad 19.5$

Black, non-Hispanic

$14 \quad 17.1$

Asian/Pacific Islander

$2 \quad 2.4$

Other

$2 \quad 2.4$

Total

$82 \quad 100.0$

\section{Credentials $^{\mathrm{b}}$}

Registered Nurse

$51 \quad 60.7$

Licensed Social Worker

$7 \quad 8.3$

Licensed Practical Nurse

$5 \quad 6.0$

Registered Dietitian

$0 \quad 0.0$

Other

$\begin{array}{ll}7 & 8.3\end{array}$

\section{Previous discharge planning preparation $^{2}$}

$\begin{array}{lrr}\text { Yes } & 51 & 61.4 \\ \text { No } & 32 & 38.6 \\ \text { Total } & \mathbf{8 3} & \mathbf{1 0 0 . 0}\end{array}$

\footnotetext{
${ }^{\mathrm{a}}$ Sample size is $<84$ due to non-responses.

"Each credential was analyzed separately and recorded as "yes" or "no." Therefore, total $\neq 100 \%$.
} 


\section{Table 2}

Average daily case load, time spent in discharge planning, and perceived barriers by discharge planning professionals

\begin{tabular}{lrr}
\hline Variable & No. & \multicolumn{1}{c}{$\%$} \\
\hline Average daily case load & & \\
$<10$ & 15 & 20.5 \\
$10-19$ & 20 & 27.4 \\
$20-39$ & 37 & 50.7 \\
$40-49$ & 1 & 1.4 \\
Total & $\mathbf{7 3}$ & $\mathbf{1 0 0 . 0}$
\end{tabular}

\section{Average daily time spent in discharge planning} $<25 \%$ $25-50 \%$ $\begin{array}{ll}6 & 7.3\end{array}$

$51-75 \%$ $31 \quad 37.8$

$>75 \%$

$15 \quad 18.3$

Total

$30 \quad 36.6$

$82 \quad 100.0$

\section{Perceived barriers $^{\mathrm{a}}$}

Excessive patient load

$44 \quad 53.0$

Too many daily responsibilities

$39 \quad 47.0$

Limited community services

$31 \quad 37.3$

Difficulty coordinating post discharge services

$16 \quad 19.3$

No barriers

$2 \quad 2.4$

Other

$12 \quad 14.6$

${ }^{a}$ Multiple answers were possible; therefore, total $=>100 \%$. 


\section{Table 3}

Healthcare professionals deemed "very important" to discharge

planning professionals $(n=83)$ in the discharge planning process

\begin{tabular}{lcc}
\hline Healthcare Professionals & No. & \% \\
\hline & & \\
Medical Doctor & 68 & 81.9 \\
Registered Nurse & 61 & 73.5 \\
Social Worker & 54 & 65.1 \\
Physical Therapist & 49 & 59.0 \\
Pharmacist ${ }^{\mathrm{a}}$ & 25 & 30.5 \\
Occupational Therapist $_{\text {Registered Dietitian }}$ & 23 & 27.7 \\
Speech Therapist & 22 & 26.5 \\
${ }^{\mathrm{a}} \mathrm{n}=82$ & 22 & 26.5 \\
\hline
\end{tabular}

\section{Table 4}

Time spent by discharge planning professionals in consulting healthcare professionals

\begin{tabular}{|c|c|c|c|c|c|}
\hline \multirow[b]{2}{*}{$\begin{array}{l}\text { Professionals } \\
\text { consulted }^{\mathrm{a}}\end{array}$} & \multicolumn{5}{|c|}{ Percent of time } \\
\hline & $\begin{array}{l}75-100 \% \\
\text { No. }(\%)^{b} \\
\end{array}$ & $\begin{array}{l}50-74 \% \\
\text { No. }(\%) \\
\end{array}$ & $\begin{array}{l}25-49 \% \\
\text { No. }(\%) \\
\end{array}$ & $\begin{array}{r}1-24 \% \\
\text { No. }(\%) \\
\end{array}$ & $\begin{array}{r}0 \% \\
\text { No. }(\%) \\
\end{array}$ \\
\hline Medical doctor & $56(68.3)$ & $18(22.0)$ & $6(7.3)$ & $2(2.4)$ & $0(0.0)$ \\
\hline Registered nurse & $47(57.0)$ & $18(21.7)$ & $14(16.9)$ & $3(3.6)$ & $1(1.2)$ \\
\hline Social worker & $36(46.2)$ & $19(24.4)$ & $12(15.4)$ & $7(9.0)$ & $4(5.1)$ \\
\hline Physical therapist & $28(34.1)$ & $34(41.5)$ & $11(13.4)$ & $3(3.7)$ & $6(7.3)$ \\
\hline Occupational therapist & $7(8.6)$ & $19(23.5)$ & $24(29.6)$ & $23(28.4)$ & $8(9.9)$ \\
\hline Speech therapist & $7(8.8)$ & $13(16.3)$ & $22(27.5)$ & $27(33.8)$ & $11(13.8)$ \\
\hline Registered dietitian & $3(3.7)$ & $14(17.3)$ & $27(33.3)$ & $24(29.6)$ & $13(16.0)$ \\
\hline Pharmacist & $2(2.5)$ & $11(13.8)$ & $23(28.8)$ & $30(37.5)$ & $14(17.5)$ \\
\hline \multicolumn{6}{|c|}{$\begin{array}{l}{ }^{a} \text { Each healthcare professional was asked and analyzed as a separate question. Sample size } \\
\text { for each question ranged from } n=78-83 \text {; therefore, percentages are based on varying } \\
\text { sample sizes. } \\
\text { b Number (\%) of discharge planning professionals }\end{array}$} \\
\hline
\end{tabular}




\section{Table 5}

Nutrition-related factors and resources affecting post discharge care

\begin{tabular}{|c|c|c|}
\hline Factors "strongly influencing" the post discharge care plan ${ }^{a}$ & No. & $\%$ \\
\hline Swallowing difficulty & 81 & 100.0 \\
\hline Physical disability & 81 & 98.8 \\
\hline Poor appetite & 80 & 97.6 \\
\hline Lives alone & 79 & 96.3 \\
\hline Walking difficulty & 75 & 92.6 \\
\hline Underweight & 74 & 91.4 \\
\hline Vision difficulty & 74 & 90.2 \\
\hline Modified diet & 73 & 89.0 \\
\hline Nausea & 73 & 89.0 \\
\hline Overweight & 73 & 89.0 \\
\hline Poor dentition & 72 & 88.9 \\
\hline Medicaid & 72 & 87.8 \\
\hline Medicare & 69 & 84.1 \\
\hline Driving ability & 68 & 86.1 \\
\hline
\end{tabular}

\begin{tabular}{lcc}
\hline Perceived readily available community resources & No. & \% \\
Transportation services & 65 & 79.3 \\
Home delivered meals & 62 & 75.6 \\
Adult day care & 61 & 74.4 \\
Area Agency on Aging & 54 & 65.9 \\
Food stamps & 39 & 47.6 \\
Congregate meals & 34 & 42.5 \\
Shopping assistance & 33 & 40.2 \\
Home modifications/repairs & 15 & 18.3 \\
Serving Health Insurance Needs of Elders (SHINE) & 15 & 18.3 \\
Outpatient registered dietitians & 8 & 9.8 \\
Farmers' market coupon program & 5 & 6.2 \\
Volunteer opthamologists & 3 & 3.7
\end{tabular}

\footnotetext{
${ }^{a}$ Each factor and community resource was asked and analyzed separately. Sample size for each question ranged from $\mathrm{n}=79$ to 82 . Therefore, percentages are based on varying sample sizes.
} 


\section{APPENDICES}

Appendix 1: Letter to discharge planning professionals. ............ 57

Appendix 2: Questionnaire. ........................... 58 


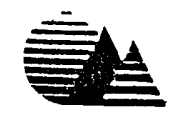

Dear Discharge Planner/Case Manager:

Enclosed is a short questionnaire that will take no more than 10 minutes to complete. Discharge Planners and Case Managers in South Florida hospitals are being asked to complete this questionnaire as part of a research study at Florida International University by Etty Baker, Principal Investigator, under the direction of Professor Nancy Wellman. We hope to learn more about the discharge planning process. Your opinions and comments are extremely important and we thank you for your participation in advance.

By completing the questionnaire, you will be providing consent to be a participant in this study. There are no identifiable risks or benefits to you for participating this confidential survey. All Discharge Planners/Case Managers and their respective hospitals will remain confldential, as there is no identifying information on the questionnaire by which we can link you personally to your responses. Survey results will be reported and presented in group format only. If you choose not to participate, no further action is required by you. If you decide to participate, you will receive a small health-promoting gift, a step counter from the Center's Steps to Healthy Aging Campaign.

If you have questions regarding this study, you may contact Dr. Nancy Wellman at 305-348-1517. If you have any questions regarding being a human subject, you may contact Dr. Bernard Gerstman, the Chairperson of Florida International University's Institutional Review Board, at 305-348-3115.

Thank you so much for taking time to complete this questionnaire.

Sincerely,

Etty B. Baker

Principal Investigator
Nancy S. Wellman, PhD, RD

Professor and Director 
Please clrcle only one answer per question unless otherwise specifled. Yoúr participation and candid responses are greatly appreclatedl Please note that data from this questlonnaire will be grouped to assure confidentlality.
1. Gonder:
A) Male
B) Female

2. Age:

A) $20-29$

B) $30-39$

C) $40-49$

D) $50-59$

E) $60+$

3. Race/Ethnic Background: $\quad$ A) White, not Hispanic origin B) Black, not Hispanic origin
C) Hispanic
D) American Inḍlan/Alaskan Native
E) Asian/Pacific Islander
F) Other

4. Job Titlo deflned by Human Resources:
A) Discharge Planner
B) Case Manager
C) Other, specify:

5. Professional Credentlals: (Circle all that apply)A) RN

B) LPN

c) LCSW
D) RD
E) Other, specify:

6. Academic Credentlals:
A) Diploma
B) Associate's Degree
C) Bachelor's Degreo

D) Master's Degree

E) Other, specify:

7. Current Certifications:
A) $\mathrm{CCM}$
B) CPUR
C) Other, specify:
D) None

8. Have you had speciffe proparation in discharge planning? A) No B) Yes, specify:

9. How many years have you worked as a discharge planner in your current facility?
A) 0-2
B) 3-5
C) $6-8$
D) $9-11$
E) $12+$

10. What is your average dlschargo planning case load/day? A) $<10$

B) $10-19$
C) $20-29$
D) $30-39$
E) Other, specify

11. How much of your time ls spent discharge planning/day? A) $<25 \%$

B) $25 \%-50 \%$

C) $51 \%-75 \%$

D) $>75 \%$

12. As a dlscharge planner/case manager, what do you consider to be the greatest challenges In your job? (Circle all that apply)
A) too many daily responsibilities
B) excessive patjent case load .
C) difficulty coordinating services post discharge
D) limited community services available
E) no barriers
F) other, specify: 
For the following questlons, please check the one box that corresponds to your answer.

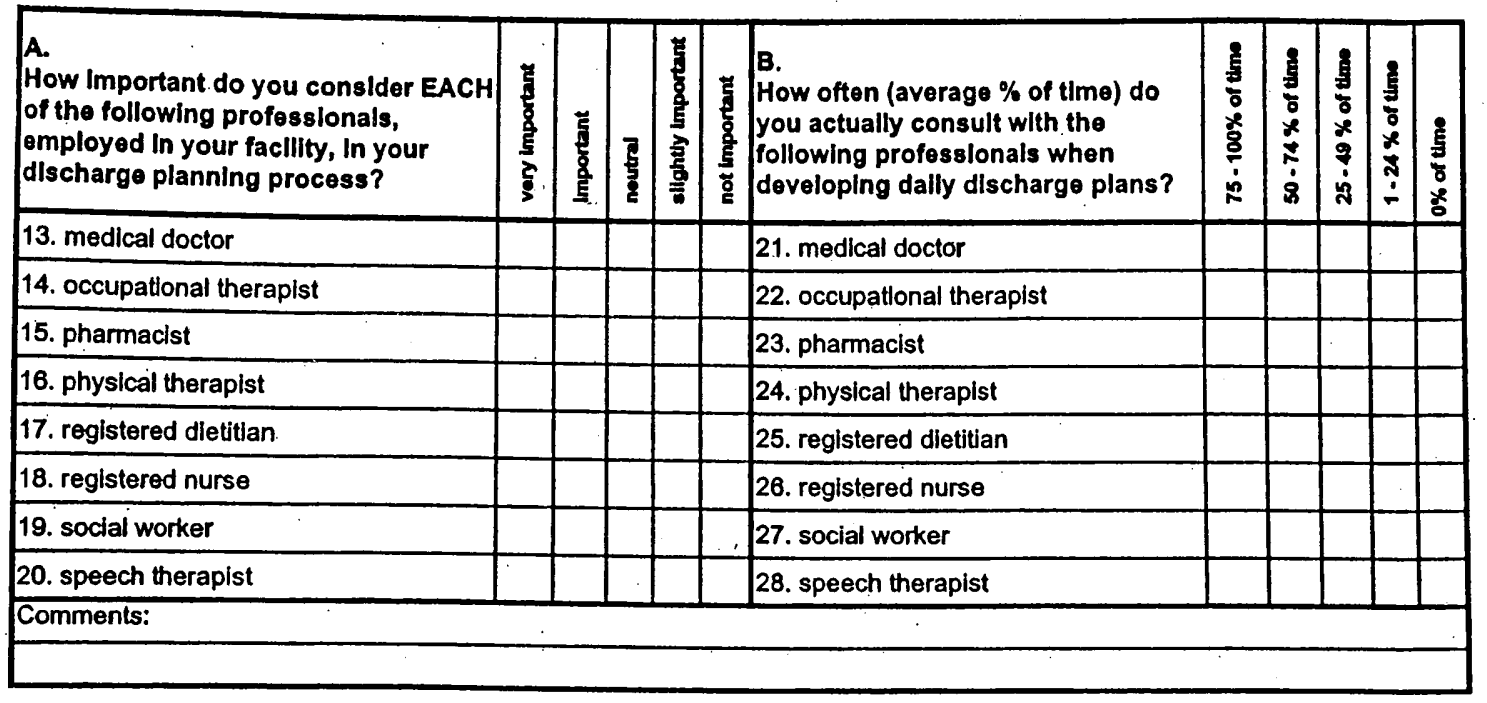

\begin{tabular}{|c|c|c|c|c|c|c|c|c|c|c|c|}
\hline $\begin{array}{l}\text { C. } \\
\text { How do the following factors } \\
\text { influence the nutrltion care that you } \\
\text { plan for an older adult } \\
\text { post-dlscharge? }\end{array}$ & 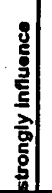 & ș & $\overline{\mathbf{5}}$ & 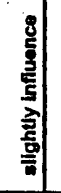 & \begin{tabular}{l|}
8 \\
$\frac{8}{5}$ \\
\\
\end{tabular} & $\begin{array}{l}\text { D. } \\
\text { Which of the following medlcal } \\
\text { conditlons Influence the nutrition } \\
\text { care that you plan for an older adult } \\
\text { post-dlscharge? }\end{array}$ & 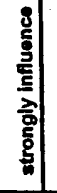 & 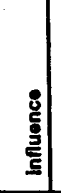 & - & 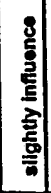 & 空 \\
\hline 29. drtving ablity & & & & & & 43. AJDS & & & & & \\
\hline 30. lives alone & & & & & & 44. cancer & & & & & \\
\hline 31. poor appetite & & & & & & 45. cardiac condition & & & & & \\
\hline 32. Medicald reciplent & & & & & & 46. depression & & & & & \\
\hline 33. Medicare reciplent & & & & & & 47. dlabetes & & & & & \\
\hline 34. misaligned dentures/poor dentition & & & & & & 48. HIV & & & & & \\
\hline 35. modified dlet & & & & & & 49. home TPN & & & & & \\
\hline 36. nausea & & & & & & 50. home tube feeding & & & & & \\
\hline 37. overwelght & & & & & & 51. hypertention & & & & & \\
\hline 38. physical dlsability & & & & & . & 52. Intestinal problems & & & & & \\
\hline 39. swallowing difficulty & & & & & & 53. post operation & & & & & \\
\hline 40. underwelght & & & & & & 54. pressure ulcers & & & & & \\
\hline 41. vision difficulty & & & & & & 55. renal fallure & & & & & \\
\hline 42. walking difficulty & & & & & & 56. stroke & & & & & \\
\hline
\end{tabular}




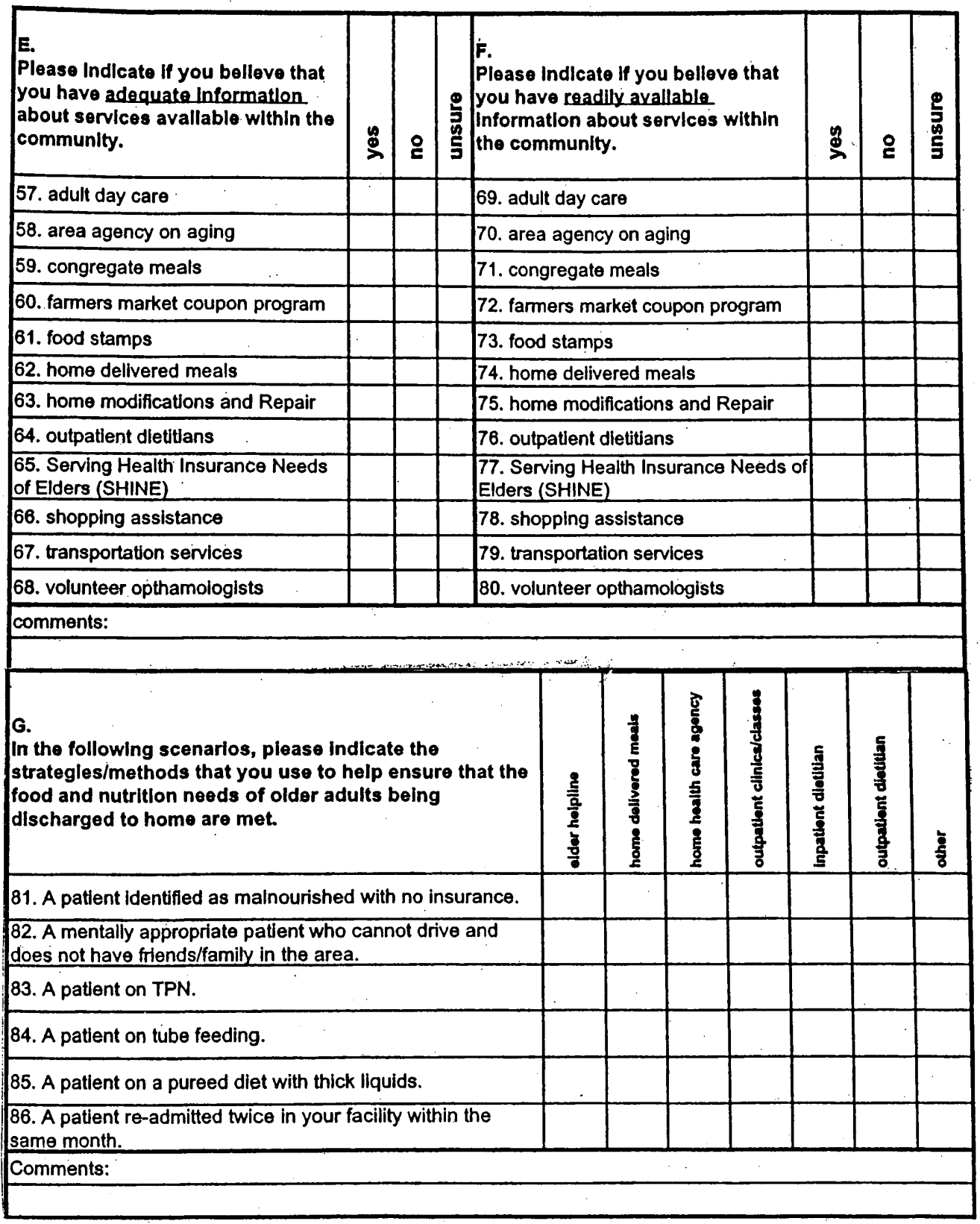

